Korey Bartolomeo, DO Department of Kidney Medicine,

Glickman Urological \& Kidney

Institute, Cleveland Clinic,

Cleveland, $\mathrm{OH}$
Xin Yee Tan, MD

Department of Kidney Medicine,

Glickman Urological \& Kidney

Institute, Cleveland Clinic,

Cleveland, $\mathrm{OH}$
Richard Fatica, MD

Vice-chair, Department of Kidney Medicine,

Glickman Urological \& Kidney Institute,

Cleveland Clinic; Clinical Assistant Professor,

Cleveland Clinic Lerner College of Medicine

of Case Western Reserve University,

Cleveland, $\mathrm{OH}$

\title{
Extraosseous calcification in kidney disease
}

\section{ABSTRACT}

A consequence of chronic and end-stage kidney disease is a higher risk of calcium deposition in sites other than the bones. The authors of this review outline current understanding of the pathogenesis, presentation, diagnosis, and treatment of this group of disorders.

\section{KEY POINTS}

Extraosseous calcification is a broad term that encompasses vascular calcification, soft tissue calcification, and calciphylaxis, all of which are seen in patients with end-stage kidney disease.

The pathogenesis of extraosseous calcification is an active process involving a complex interplay of abnormal electrolyte levels, cell differentiation, and dysregulation of many biochemical pathways.

Vascular calcification is predominantly diagnosed incidentally, while soft tissue calcification and calciphylaxis are diagnosed on the basis of radiographic and clinical presentation, sometimes requiring biopsy.

Management is based on low-quality evidence and includes maintaining a neutral calcium balance, correcting hyperphosphatemia, and controlling comorbidities. Surgical and other nonmedical therapies may help somewhat in managing calciphylaxis and soft tissue manifestations.
CHRONIC KIDNEY DISEASE, DEFINED as an estimated glomerular filtration rate (eGFR) less than $60 \mathrm{~mL} / \mathrm{min} / 1.73 \mathrm{~m}^{2}$ or structural kidney damage sustained over 3 months, is increasing in prevalence worldwide. It is estimated to affect between $2 \%$ and $17 \%$ of all adults, and the United States is at the high end of this prevalence range. ${ }^{1}$

As chronic kidney disease progresses, it leads to higher rates of bone mineral disease, a systemic disorder involving the following:

- Abnormalities in serum calcium, phosphate, parathyroid hormone (PTH), and vitamin D levels

- Disorders of bone metabolism (renal osteodystrophy)

- Calcium deposition in both vascular and soft tissues. ${ }^{2}$

Patients with end-stage kidney disease are at high risk of complications from disorders of bone metabolism, which are strongly associated with increased rates of cardiovascular and all-cause mortality. ${ }^{3-6}$

\section{NAMES AND PRESENTATIONS}

Extraosseous tissue calcification can involve both vascular tissues (arteries and heart valves) and soft tissues. A variety of terms have been used to describe it, based on the location and the type of tissue involved (Table 1), but subclassifying it precisely and studying its prevalence are challenging because its presentation is heterogeneous.

\section{REGULATION OF CALCIUM AND PHOSPHATE}

Serum calcium and phosphate levels are kept under tight control by regulatory hormones 


\section{TABLE 1}

\section{Common terms used to describe calcification}

\section{Soft tissue calcification}

Dystrophic calcification: occurring in damaged or degenerated tissue in the setting of normal metabolic factors

Metastatic calcification: occurring in otherwise normal tissue, secondary to deranged metabolic factors, as in hypercalcemia

Calciphylaxis (calcific uremic arteriopathy): ischemic skin lesions characterized by calcium deposition and thrombosis in the dermis and subcutaneous adipose tissue, most commonly associated with advanced kidney disease

Calcinosis cutis universalis: diffuse involvement of subcutaneous and fibrous structures, most commonly in association with autoimmune disorders

Tumoral calcinosis: massive deposition of calcium-phosphorus crystals in periarticular areas

Calcinosis circumscripta: localized or isolated calcification; term sometimes used if calciphylaxis involvement is limited to an extremity

\section{Vascular calcification}

Atherosclerotic (intimal) calcification: inflammatory vaso-occlusive calcification of intima as a result of endothelial dysfunction

Monckeberg arterial calcification: medial calcification deposition in small and medium arteries without luminal narrowing

Infantile calcification: extensive calcification of medium and large arteries due to ENPP1 gene mutation

released by various organs, with complex feedback mechanisms (Figure 1).

Interestingly, both calcium and phosphate are regulated by the same hormone, ie, PTH. ${ }^{7,8}$ When serum calcium levels are low and serum phosphate levels are high, the parathyroid glands release more PTH, which acts in several organs to raise the calcium and, on the whole, to lower the phosphate levels.

In the kidney, PTH directly increases calcium reabsorption in the distal tubule and loop of Henle and increases phosphate excretion by inhibiting its reabsorption in the proximal tubule. ${ }^{9,10}$ Also in the kidney, PTH upregulates production of 1 alpha-hydroxylase, leading to increased conversion of active vitamin D (1,25-dihydroxycholecalciferol) from its precursor, 25-hydroxycholecalciferol. In turn, in the intestine, active vitamin D increases the absorption of calcium and to a lesser degree phosphate, and in the bone, it has direct actions on both osteoblasts and osteocytes, promoting maturation, expression of skeletal hormones such as fibroblast growth factor 23 (FGF-23), and proper mineralization. ${ }^{11,12}$

FGF-23 is an important skeletal hormone that lowers phosphate levels by promoting its wasting (ie, suppressing its reabsorption) in the kidney, suppressing its absorption in the intestine, and, in a negative feedback loop, lowering both PTH and 1,25-dihydroxycholecalciferol production. ${ }^{13}$ Klotho, a protein that has multiple effects in many tissues, facilitates binding of FGF-23 to FGF receptor 1 in the kidney, leading to fewer phosphate receptors in the proximal convoluted tubules, more phosphate excreted in the urine, and lower serum phosphate levels. ${ }^{14}$ The net effect of these interactions is homeostatic balance in serum calcium and phosphate levels.

\section{CALCIUM-PHOSPHATE AXIS DERANGEMENTS}

In chronic kidney disease, nephrons are progressively lost. Among the ill effects is a higher phosphate level, which in turn upregulates production of FGF-23 by the osteocytes and osteoblasts and leads to bone mineral disease (Figure 1). Bone mineral disease can begin early in the course of chronic kidney disease, ${ }^{15}$ when the eGFR may still be as high as $69 \mathrm{~mL} /$ $\min / 1.73 \mathrm{~m}^{2}$. Meanwhile, klotho production is downregulated, so that less FGF-23 binds to its receptor in the kidney, ${ }^{16,17}$ less 1 alpha-hydroxylase and active vitamin D are produced, and more phosphate is reabsorbed in the proximal convoluted tubule. . $^{18,19}$

As chronic kidney disease progresses to its end stage, FGF-23 levels keep getting higher, and the elevation is accompanied by other calcium-phosphate axis derangements such as excess PTH release, decreased 1,25-dihydroxycholecalciferol, and increased sclerostin (an inhibitor of bone formation). ${ }^{20,21}$ Together, these derangements lead to the clinical manifestations described below.

\section{Vascular calcification}

Vascular calcification is an active process involving de-differentiation of vascular smooth muscle cells. It begins with amorphous development of calcium phosphate nanocrystals in con- 


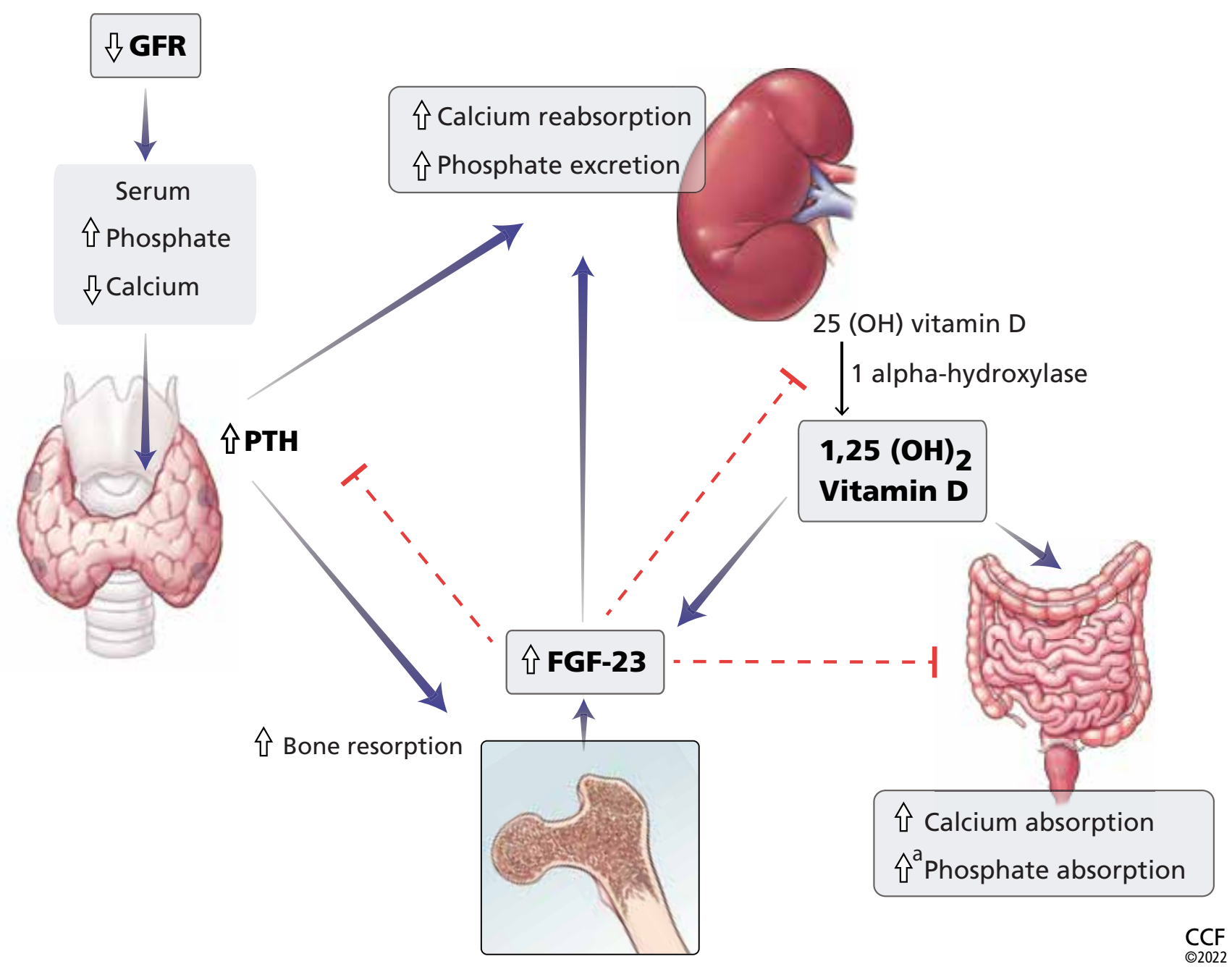

Figure 1. Calcium and phosphate metabolism in chronic kidney disease. Decreased glomerular filtration rate (GFR) leads to changes in serum calcium and phosphate, triggering release of parathyroid hormone (PTH) from the parathyroid glands and fibroblast growth factor 23 (FGF-23) from osteoblasts and osteocytes. These hormones have complex downstream effects on the kidney, gut, and bone, both from direct effects on the tissue and from indirect effects through modulation of enzyme activity in vitamin D conversion.

a Minimally increased.

$25(\mathrm{OH})$ vitamin $\mathrm{D}=25$-hydroxycholecalciferol; $1,25(\mathrm{OH})_{2}$ vitamin $\mathrm{D}=1,25$-dihydroxycholecalciferol

junction with other calcium-regulatory proteins in the wall of the artery. ${ }^{22}$ Deposition of these nanocrystals can begin in the intima of the artery near sites of cholesterol buildup, either progressing into the media or beginning in the media itself, the latter of which is most specific to kidney disease.

In end-stage kidney disease, progression of vascular calcification occurs earlier than in normal aging and is likely driven by hyperphosphatemia, a positive calcium balance, inflammation, and dysregulation between procalcification and anticalcification regulatory factors. An in-depth discussion of the pathogenesis of vascular calcification is beyond the scope of this paper and can be found elsewhere. $^{23}$

\section{Soft tissue calcification}

Soft tissue calcification is fairly common in chronic and end-stage kidney disease, but only a small number of patients develop tu- 


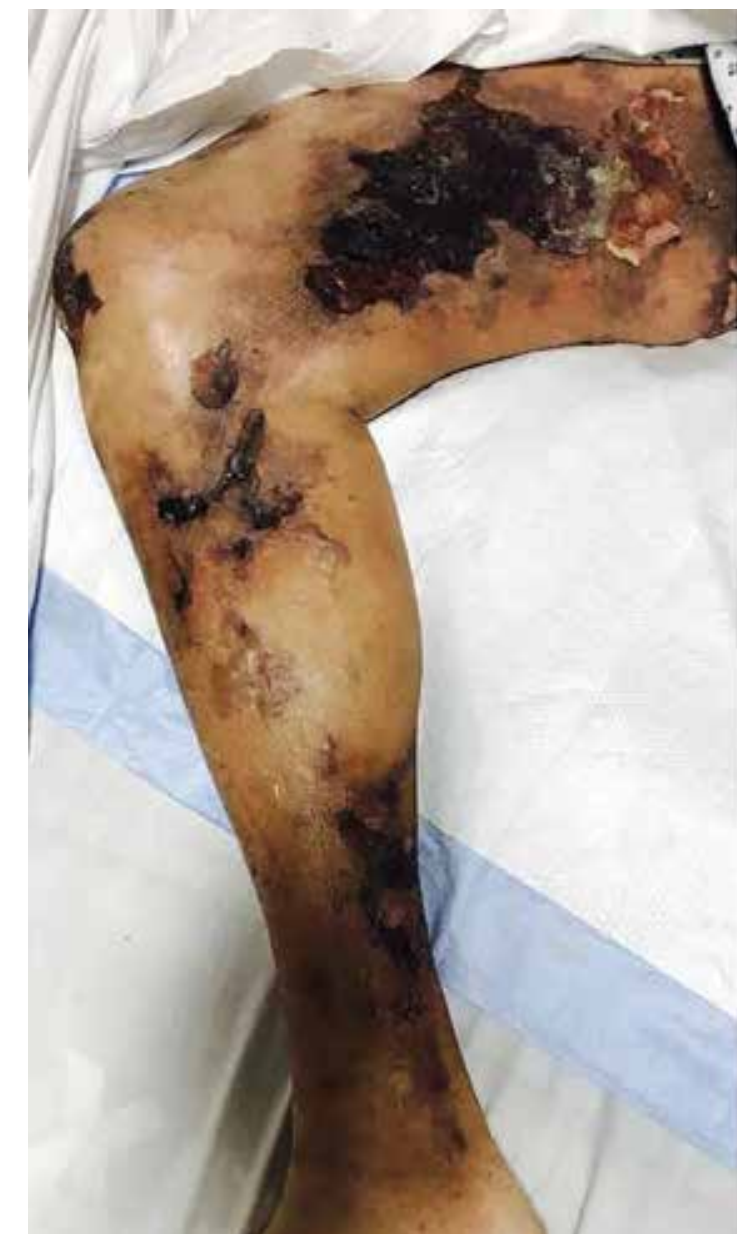

Figure 2. Calciphylaxis in a 51-year-old man with end-stage kidney disease.

From reference 27 .

moral calcinosis, characterized by massive calcium phosphate deposition in periarticular locations predisposed to microtrauma.

Tumoral calcinosis is well described in families, with autosomal-recessive inheritance stemming from a number of genes, including loss-of-function mutation of FGF23 and missense mutation of alpha-Klotho, contributing to the hyperphosphatemia. ${ }^{24}$ Hyperphosphatemia is likely a necessary contributor to these familial forms of tumoral calcinosis, but it may also explain their presence in chronic and end-stage kidney disease, stemming from local tissue production or from exogenous phosphate retention..$^{25,26}$

\section{PRESENTATION AND DIAGNOSIS}

Calciphylaxis is intensely painful, unlike other presentations (Figure 2). ${ }^{27}$ It is most commonly seen in adipose-dense tissues but can develop centrally and in appendicular areas, including the genital regions. Skin lesions can vary from induration to ulceration with eschar formation. ${ }^{28}$ Its diagnosis is predominantly clinical. A skin biopsy to the depth of the subcutaneous tissue can aid diagnosis but poses significant procedural risks that include pain intensification, poor healing, and secondary infection. ${ }^{29}$

Soft tissue calcifications, in contrast, are usually painless, unless radicular symptoms develop from mass effect. Instead, there is typically a decrease in range of motion of the affected joints, ${ }^{30}$ of which (in descending order of frequency) the hip, elbow, shoulder, foot, and wrist are most commonly affected (Figure 3). ${ }^{31}$ Soft tissue calcifications tend to be formally diagnosed based on the location of the calcium deposition, in addition to morphologic descriptions to rule out cancer mimickers.

Vascular calcification. Traditional risk factors that predict atherosclerotic calcification do not fully explain the high prevalence of vascular calcification in patients with chronic and end-stage kidney disease. Additional potentially modifiable risk factors related to kidney disease or its treatment have been shown to accelerate calcification (Table 2). ${ }^{32}$

\section{MEDICAL THERAPY}

Most of the research has focused on therapies directed at vascular calcification, given its clinical implications with cardiovascular disease in end-stage kidney disease.

\section{Dietary phosphate restriction, phosphate binders}

Given the central role of elevated phosphate and FGF-23 in the pathogenesis of extraosseous calcification, controlling serum phosphate levels, first through dietary phosphate restriction and then with intestinal phosphate binders, is a logical and low-cost management choice in preventing vascular calcification.

The most commonly used phosphate intestinal binders are calcium-based (eg, calcium carbonate, calcium acetate) and are used extensively in patients with chronic and end-stage kidney disease for many indications. 
However, earlier studies demonstrated a relationship between higher calcium intake and higher rates of vascular calcification, ${ }^{33}$ and subsequent studies called attention to this association, leading to recommendations for using non-calcium-based intestinal phosphate binders to restore normal phosphate levels while limiting calcium intake to maintain normal serum calcium. . $^{34,35}$

A number of randomized trials over the last 20 years have attempted to settle the debate on calcium-based vs non-calcium-based phosphate binders and cardiovascular disease, many of them using vascular calcification as a surrogate end point.

The IMPROVE-CKD trial ${ }^{36}$ (Impact of Phosphate Reduction on Vascular End-points in Chronic Kidney Disease) tested lanthanum use in patients with advanced chronic kidney disease $\left(e G F R<30 \mathrm{~mL} / \mathrm{min} / 1.73 \mathrm{~m}^{2}\right)$ and evaluated changes in aortic calcification and arterial stiffness. It did not find statistically significant differences with lanthanum compared with placebo. Of note, the trial was limited by recruitment, including patients with normal phosphate levels and excluding those with end-stage kidney disease. ${ }^{36}$

The Treat-to-Goal study ${ }^{37}$ in patients with end-stage kidney disease on hemodialysis found less coronary artery and aortic calcification and a lower incidence of hypercalcemia in those randomized to sevelamer compared with calcium acetate. These results may correlate with improved all-cause survival rates in patients newly started on hemodialysis, despite lower rates of normophosphatemia when sevelamer is used. ${ }^{15,38}$ Subsequent studies comparing lanthanum carbonate with calcium carbonate in patients newly starting on hemodialysis did not find statistically significant differences in calcification scores in heart valves. ${ }^{39}$

The LANDMARK trial ${ }^{40}$ (Outcome Study of Lanthanum Carbonate Compared With Calcium Carbonate on Cardiovascular Mortality and Morbidity in Patients With Chronic Kidney Disease on Hemodialysis), published in 2021, looked at patients with end-stage kidney disease in Japan who had risk factors for vascular calcification who were randomized to receive lanthanum or calcium carbonate. It did not find any statistically significant differences
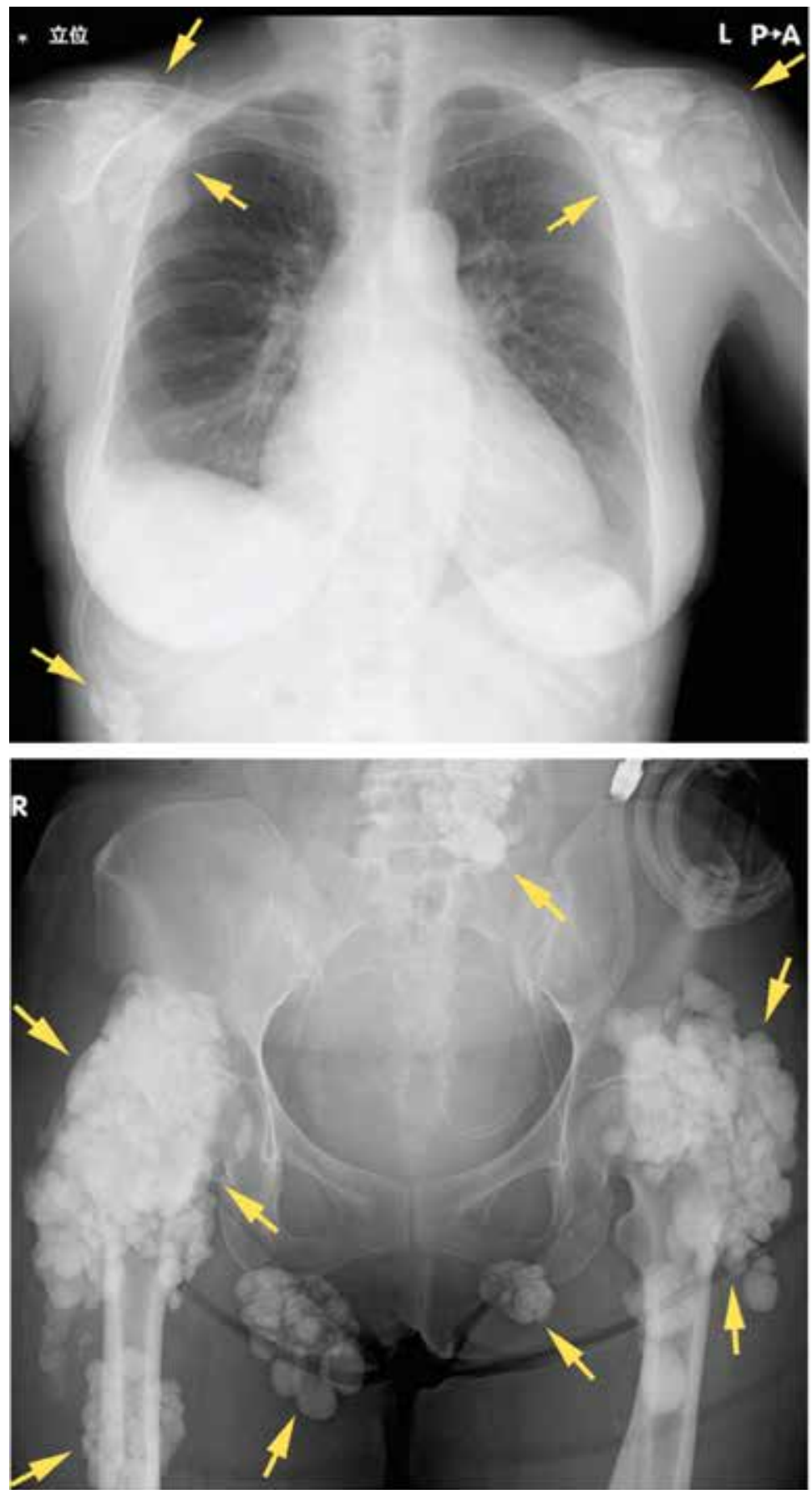

Figure 3. Radiography shows calcified masses (arrows) in a 47-year-old woman with tumoral calcinosis.

From reference 30

in rates of all-cause mortality or cardiovascular events between the two groups, though the event rates were low. Further, compared with the United States, Japan has lower dietary calcium intake, higher use of arteriovenous fistulas 


\section{TABLE 2}

\section{Risk factors associated with vascular calcification}

\section{Traditional risk factors}

Hypertension

Diabetes mellitus

Old age

Smoking

Dyslipidemia

Family history of premature coronary artery disease

Male sex

Increased levels of C-reactive protein or other inflammatory markers

\section{Kidney disease-related risk factors}

Longer hemodialysis duration

Persistent hyperphosphatemia

Increased calcium-phosphate product

Calcium-containing phosphate binders

Secondary hyperparathyroidism

Vascular calcification increases cardiovascular risk
Adynamic bone disease

Vitamin D deficiency and excessive vitamin $\mathrm{D}$ administration

High dialysate calcium

Hypomagnesemia

Low fetuin-A

Low albumin

for dialysis access, and different cardiovascular screening practices, which could limit wide applicability of the results. ${ }^{40}$

In sum, data conflict regarding whether non-calcium-based intestinal phosphate binders are superior to calcium-based binders in preventing vascular calcification and cardiovascular events.

\section{Bone antiresorptive agents}

Pyrophosphates (bisphosphonates), the most commonly used class of drugs for preventing bone resorption, inhibit the activity of osteoclasts, and some of these drugs also induce apoptosis. Bisphosphonates are either retained in the bone or cleared by the kidney.

Robust data exist for using this drug class in bone disorders in patients in the early stages of chronic kidney disease (eGFR $>35 \mathrm{~mL}$ / $\mathrm{min} / 1.73 \mathrm{~m}^{2}$ ), but data are significantly limited in those with stage 4 or 5 chronic kidney disease or end-stage kidney disease, and there are theoretical safety concerns. ${ }^{41}$ Bisphosphonates are less frequently prescribed in these latter populations, possibly due to concerns about toxicity, as these drugs are excreted by the kidney. ${ }^{42}$ Reports of worsening kidney disease or kidney injury exist for most drugs in the bisphosphonate class, but larger observational trials have found oral bisphosphonates to be reasonably safe in advanced chronic kidney disease, though bisphosphonate users had a $14 \%$ higher risk of progression of chronic kidney disease. ${ }^{43}$

Zoledronic acid, a potent intravenous formulation, should be avoided if the eGFR is less than $30 \mathrm{~mL} / \mathrm{min} / 1.73 \mathrm{~m}^{2}$, in view of stronger associations with direct tubular injury, acute kidney injury, and worsened eGFR.44,45 Pamidronate is generally the preferred intravenous formulation for patients with advanced chronic kidney disease, usually given at a lower dose or infused over a longer time. Rarely, collapsing focal segmental glomerulosclerosis can occur. ${ }^{44,45}$

Bisphosphonates have been shown to reduce both overall vascular calcification and all-cause mortality in certain groups (eg, patients with osteoporosis or cancer), but not the rate of cardiovascular events. ${ }^{46}$ Etidronate, a first-generation bisphosphonate now discontinued due to high rates of osteomalacia, was used to treat soft tissue calcifications. ${ }^{47-49}$ Etidronate also reduced vascular calcification in rat models of chronic kidney disease, while human studies showed reduced coronary artery calcification in patients with advanced chronic kidney disease and end-stage kidney disease. ${ }^{49-51}$ Newer bisphosphonates have limited data on their effects on vascular calcification in end-stage kidney disease, with one study of alendronate showing no improvement in coronary artery calcification score..$^{52}$

Denosumab, a RANK ligand inhibitor (RANK stands for receptor activator of 
nuclear factor kappa B) that prevents osteoclast maturation, has not been studied in soft tissue calcification. Small pilot studies have looked at denosumab's effects on vascular calcification in humans and have suggested it may slow coronary artery calcification, but this has been challenged in other studies. ${ }^{52,53}$ More studies are needed to determine the clinical significance of these findings. We are not aware of any studies that have looked at denosumab in soft tissue calcification or calciphylaxis.

Teriparatide is a synthetic formulation of PTH. The only evidence for using it to treat tumoral calcinosis comes from case reports, and no major studies have looked at using it in end-stage kidney disease to prevent vascular calcification. ${ }^{54}$

\section{Calcimimetics}

Calcimimetics are drugs that bind allosterically to the calcium-sensing receptor on parathyroid cells to suppress PTH release for a given serum calcium level.

Cinacalcet, the most common drug in this class, has been studied extensively in secondary hyperparathyroidism in 2 trials, the EVOLVE $^{55}$ (Evaluation of Cinacalcet Hydrochloride Therapy to Lower Cardiovascular Events) and ADVANCE ${ }^{56}$ (A Randomized Study to Evaluate the Effects of Cinacalcet plus Low-Dose Vitamin D on Vascular Calcification in Subjects With Chronic Kidney Disease Receiving Heemodialysis). It did not show improvement in aortic calcification or reduction in cardiovascular outcomes or allcause mortality despite improvements in serum PTH levels. ${ }^{55,56}$ In contrast, a more recent meta-analysis of cinacalcet use in end-stage kidney disease did find a benefit in terms of lower rates of all-cause mortality and cardiovascular mortality. ${ }^{57}$ Other calcimimetics have been studied only in animal models, and thus their clinical effect in humans is undetermined.

\section{Sodium thiosulfate}

Sodium thiosulfate is an older medication with antioxidant properties that has been used off-label for years in calcium disorders including vascular calcification and calciphylaxis. It was recently systematically reviewed in treating calciphylaxis, with conflicting results. ${ }^{58,59}$
More recently, a randomized clinical trial ${ }^{60}$ showed reduction of iliac artery calcification and arterial stiffness with sodium thiosulfate compared with placebo in calciphylaxis. Ongoing prospective and randomized trials will hopefully provide clarity of the benefit of sodium thiosulfate in vascular calcification and calciphylaxis. In a small case series, the drug has shown improvement in symptom burden in soft tissue calcification of the shoulder and hip, with partial size regression. ${ }^{61}$

\section{Vitamin $\mathrm{K}$}

Vitamin $\mathrm{K}$ is an essential cofactor for carboxylation of numerous proteins, including some that inhibit vascular calcification, such as matrix G1a protein. ${ }^{62}$ Evidence that lack of vitamin $\mathrm{K}$ may be involved in vascular calcification includes a high prevalence of vitamin $\mathrm{K}$ deficiency in this population and improvement in carboxylation surrogate markers with supplementation. . $^{63,64}$

Warfarin, a vitamin $\mathrm{K}$ antagonist, accelerates medial arterial calcification, particularly in end-stage kidney disease. ${ }^{65}$ Furthermore, warfarin has been identified observationally as a risk factor for calciphylaxis, and low levels of carboxylation of matrix G1a protein are associated with calciphylaxis in end-stage kidney disease. ${ }^{66}$ The suspected mechanism by which warfarin may contribute to calciphylaxis is by inhibiting vitamin $\mathrm{K}$-dependent carboxylation of matrix G1a protein, a mineral-binding extracellular matrix protein that prevents calcium deposition in arteries.

Several phase 3 trials are being conducted to determine the benefit of vitamin K supplementation in vascular calcification and calciphylaxis, though a recent trial in patients with stage 4 chronic kidney disease ${ }^{67}$ did not show improvement in vascular stiffness with vitamin $\mathrm{K}$ supplementation. There are no current studies looking at tumoral calcinosis and vitamin $\mathrm{K}$ supplementation.

\section{Novel therapies, nonmedical management} SNF472, a myoinositol hexaphosphate that inhibits hydroxyapatite growth, has shown promise in early clinical trials in reduction of coronary artery calcium volume, while tissuenonspecific alkaline phosphatase inhibitors are in earlier stages of development. ${ }^{68,69}$
Data conflict regarding whether noncalcium-based intestinal phosphate binders are superior to calcium-based binders in preventing vascular calcification

and cardiovascular events 
Magnesium and vitamin D supplementation in chronic and end-stage kidney disease has had varying degrees of success in preventing vascular calcification, though more studies are needed to confirm its clinical utility. ${ }^{70,71}$ With particular relevance to soft tissue calcification, surgical debridement and hyperbaric oxygen therapies hold significant promise as adjunctive therapies to the aforementioned medical therapies. ${ }^{72-74}$

\section{DISCLOSURES}

Dr. Fatica has disclosed working as an advisor or review panel participant for Natera Inc and REATA Pharmaceuticals. The other authors report no relevant financial relationships which, in the context of their contributions, could be perceived as a potential conflict of interest.

\section{REFERENCES}

1. Murton M, Goff-Leggett D, Bobrowska A, et al. Burden of chronic kidney disease by KDIGO categories of glomerular filtration rate and albuminuria: a systematic review. Adv Ther 2021; 38(1):180-200. doi:10.1007/s12325-020-01568-8

2. Moe S, Drüeke T, Cunningham J, et al. Definition, evaluation, and classification of renal osteodystrophy: a position statement from Kidney Disease: Improving Global Outcomes (KDIGO). Kidney Int 2006; 69(11):1945-1953. doi:10.1038/sj.ki.5000414

3. Iseri K, Rashid Qureshi A, Dai L, et al. Bone mineral density at different sites and 5 years mortality in end-stage renal disease patients: a cohort study. Bone 2020; 130:115075. doi:10.1016/j.bone.2019.115075

4. Taal MW, Roe S, Masud T Green D, Porter C, Cassidy MJD. Total hip bone mass predicts survival in chronic hemodialysis patients. Kidney Int 2003; 63(3):1116-1120. doi:10.1046/j.1523-1755.2003.00837.x

5. Orlic L, Mikolasevic I, Crncevic-Orlic Z, Jakopcic I, Josipovic J, Pavlovic D. Forearm bone mass predicts mortality in chronic hemodialysis patients. J Bone Miner Metab 2017; 35(4):396-404. doi:10.1007/s00774-016-0766-7.

6. Disthabanchong S, Jongirasiri S, Adirekkiat S, et al. Low hip bone mineral density predicts mortality in maintenance hemodialysis patients: a five-year follow-up study. Blood Purif 2014; 37(1):33-38. doi:10.1159/000357639

7. Hannan FM, Kallay E, Chang W, Brandi ML, Thakkar RV. The calcium-sensing receptor in physiology and in calcitropic and noncalcitropic diseases. Nat Rev Endocrinol 2018; 15(1):33-51. doi:10.1038/s41574-018-0115-0

8. Centeno PP, Herberger A, Mun H-C, et al. Phosphate acts directly on the calcium-sensing receptor to stimulate parathyroid hormone secretion. Nat Commun 2019; 10(1):4693. doi:10.1038/s41467-019-12399-9

9. Edwards A, Bonny O. A model of calcium transport and regulation in the proximal tubule. Am J Physiol Renal Physiol 2018; 315(4):F942-F953. doi:10.1152/ajprenal.00129.2018

10. Bergwitz C, Jüppner H. Regulation of phosphate homeostasis by PTH, vitamin D, and FGF23. Annu Rev Med 2010; 61:91-104 doi:10.1146/annurev.med.051308.111339

11. Pereira RC, Salusky IB, Bowen RE, Freymiller EG, Wesseling-Perry K. Vitamin D sterols increase FGF23 expression by stimulating osteoblast and osteocyte maturation in CKD bone. Bone 2019; 127:626-634. doi:10.1016/j.bone.2019.07.026

12. Wesseling-Perry K, Pereira RC, Sahney S, et al. Calcitriol and doxercalciferol are equivalent in controlling bone turnover, suppressing parathyroid hormone, and increasing fibroblast growth factor-23 in secondary hyperparathyroidism. Kidney Int 2011; 79(1):112-119. doi:10.1038/ki.2010.352

13. Ho BB, Bergwitz C. FGF23 signalling and physiology. J Mol Endocrinol 2021. 66(2):R23-R32. doi:10.1530/JME-20-0178

14. Neyra JA, Hu MC, Moe OW. Klotho in clinical nephrology: diagnostic and therapeutic implications Clin J Am Soc Nephrol 2020; 16(1):162-176. doi:10.2215/CJN.02840320

15. Block GA, Raggi P, Bellasi A, Kooienga L, Spiegel DM. Mortality effect of coronary calcification and phosphate binder choice in incident hemodialysis patients. Kidney Int 2007; 71(5):438-441. doi:10.1038/sj.ki.5002059
16. Chudek J, Kocelak P, Owczarek A, et al. Fibroblast growth factor 23 (FGF23) and early chronic kidney disease in the elderly. Nephrol Dial Transplant 2014; 29(9):1757-1763. doi:10.1093/ndt/gfu063

17. Muñoz-Castañeda JR, Rodelo-Haad C, de Mier MVP-R, Martin-Malo A, Santamaria R, Rodriguez M. Klotho/FGF23 and Wnt signaling as important players in the comorbidities associated with chronic kidney disease. Toxins (Basel) 2020; 12(3):185. doi:10.3390/toxins12030185.

18. Mace ML, Gravesen E, Hofman-Bang J, Olgaard K, Lewin E. Key role of the kidney in the regulation of fibroblast growth factor 23. Kidney Int 2015; 88(6):1304-1313. doi:10.1038/ki.2015.231

19. Saki F, Kassaee SR, Salehifar A, Omrani GHR. Interaction between serum FGF-23 and PTH in renal phosphate excretion, a case-control study in hypoparathyroid patients. BMC Nephrol 2020; 21(1):176. doi:10.1186/s12882-020-01826-5

20. Pelletier S, Dubourg L, Carlier M-C, Hadj-Aissa A, Fouque D. The relation between renal function and serum sclerostin in adult patients with CKD. Clin J Am Soc Nephrol 2013; 8(5):819-823. doi:10.2215/CJN.07670712

21. Wazir, B, Duarte R, Naicker S. Chronic kidney disease-mineral and bone disorder (CKD-MBD): current perspectives. Int J Nephrol Renovasc Dis 2019: 12:263-276. doi:10.2147/IJNRD.S191156

22. Schlieper G, Aretz A, Verberckmoes SC, et al. Ultrastructural analysis of vascular calcifications in uremia. J Am Soc Nephrol 2010; 21(4):689-696. doi:10.1681/ASN.2009080829

23. Kakani E, Elyamny M, Ayach T, El-Husseini A. Pathogenesis and management of vascular calcification in CKD and dialysis patients. Semin Dial 2019; 32(6):553-561. doi:10.1111/sdi.12840

24. Farrow EG, Imel EA, White KE. Miscellaneous non-inflammatory musculoskeletal conditions. Hyperphosphatemic familial tumoral calcinosis (FGF23, GALNT3 and alph-Klotho). Best Pract Res Clin Rheumatol 2011; 25(5):735-747. doi:10.1016/j.berh.2011.10.020

25. Slavin RE, Wen J, Barmada A. Tumoral calcinosis--a pathogenetic overview: a histological and ultrastructural study with a report of two new cases, one in infancy. Int J Surg Pathol 2012; 20(5):462-473. doi:10.1177/1066896912444925

26. Fathi I, Sakr M. Review of tumoral calcinosis: a rare clinico-pathological entity. World J Clin Cases 2014; 2(9):409-414. doi:10.12998/wjcc.v2.i9.409

27. Shetty M, Chowdhury Y, Yegneswaran B. Calcific uremic arteriolopathy. Cleve Clin J Med 2018; 85(8):584-585. doi:10.3949/ccjm.85a.18009

28. Ghosh T, Winchester DS, Davis MDP, El-Azhary R, Comfere NI. Early clinical presentations and progression of calciphylaxis. Int J Dermatol 2017; 56(8):856-861. doi:10.1111/ijd.13622

29. Colboc H, Moguelet P, Bazin D, et al. Localization, morphologic features, and chemical composition of calciphylaxis-related skin deposits in patients with calcific uremic arteriolopathy. JAMA Dermatol 2019; 155(7):789-796. doi:10.1001/jamadermatol.2019.0381

30. Yano H, Kinjo M. Tumoral calcinosis. Cleve Clin J Med 2021; 88(4):208-209. doi:10.3949/ccjm.88a.20084

31. Olsen KM, Chew FS. Tumoral calcinosis: pearls, polemics, and alternative possibilities. Radiographics 2006; 26(3):871-885. doi:10.1148/rg.263055099

32. Moe SM, Chen NX. Pathophysiology of vascular calcification in chronic kidney disease. Circ Res 2004; 95(6):560-567. doi:10.1161/01.RES.0000141775.67189.98 
33. Goodman WG, Goldin J, Kuizon BD, et al. Coronary-artery calcification in young adults with end-stage renal disease who are undergoing dialysis. N Engl J Med 2000; 342(20):1478-1483. doi:10.1056/NEJM200005183422003

34. Jamal SA, Vandermeer B, Raggi P, et al. Effect of calcium-based versus non-calcium-based phosphate binders on mortality in patients with chronic kidney disease: an updated systematic review and meta-analysis. Lancet 2013; 382(9900):1268-1277. doi:10.1016/S0140-6736(13)60897-1

35. Ruospo M, Palmer SC, Natale P, et al. Phosphate binders for preventing and treating chronic kidney disease-mineral and bone disorder (CKD-MBD). Cochrane Database Syst Rev 2018; 8(8):CD006023. doi:10.1002/14651858.CD006023.pub3

36. Toussaint ND, Pedagogos E, Lioufas NM, et al. A randomized trial on the effect of phosphate reduction on vascular end points in CKD (IMPROVE-CKD). J Am Soc Nephrol 2020; 31(11):2653-2666. doi:10.1681/ASN.2020040411

37. Chertow GM, Burke SK, Raggi P. Sevelamer attenuates the progression of coronary and aortic calcification in hemodialysis patients. Kidney Int 2002; 62(1):245-252. doi:10.1046/j.1523-1755.2002.00434.x

38. Qunibi WY, Nolan CR. Treatment of hyperphosphatemia in patients with chronic kidney disease on maintenance hemodialysis: results of the CARE study. Kidney Int Suppl 2004; (90):S33-S38. doi:10.1111/j.1523-1755.2004.09006.x

39. Watanabe K, Fujii H, Kono K, Goto S, Nishi S. Comparison of the effects of lanthanum carbonate and calcium carbonate on the progression of cardiac valvular calcification after initiation of hemodialysis. BMC Cardiovasc Disord 2020; 20(1):39. doi:10.1186/s12872-020-01343-1

40. Ogata $\mathbf{H}$, Fukagawa $M$, Hirakata $H$, et al. Effect of treating hyperphosphatemia with lanthanum carbonate vs calcium carbonate on cardiovascular events in patients with chronic kidney disease undergoing hemodialysis: the LANDMARK randomized clinical trial. JAMA 2021; 325(19):1946-1954. doi:10.1001/jama.2021.4807

41. Toussaint ND, Elder GJ, Kerr PG. Bisphosphonates in chronic kidney disease; balancing potential benefits and adverse effects on bone and soft tissue. Clin J Am Soc Nephrol 2009; 4(1):221-233. doi:10.2215/CJN.02550508

42. Titan SM, Laureati $\mathbf{P}$, Sang $\mathbf{Y}$, et al. Bisphosphonate utilization across the spectrum of eGFR. Arch Osteoporos 2020; 15(1):69. doi:10.1007/s11657-020-0702-2

43. Robinson DE, Ali MS, Pallares N, et al. Safety of oral bisphosphonates in moderate-to-severe chronic kidney disease: a binational cohort analysis. J Bone Miner Res 2021: 36(5):820-832. doi:10.1002/jbmr.4235

44. de Roij van Zuijdewijn C, van Dorp W, Florquin S, Roelofs J, Verburgh $\mathrm{K}$. Bisphosphonate nephropathy: a case series and review of the literature. Br J Clin Pharmacol 2021; 87(9):3485-3491. doi:10.1111/bcp. 14780

45. Perazella MA, Markowitz GS. Bisphosphonate nephrotoxicity. Kidney Int 2008; 74(11):1385-1393. doi:10.1038/ki.2008.356

46. Kranenburg G, Bartstra JW, Weijmans M, et al. Bisphosphonates for cardiovascular risk reduction: a systematic review and meta-analysis. Atherosclerosis 2016; 252:106-115. doi:10.1016/j.atherosclerosis.2016.06.039

47. Russell RG, Smith R, Bishop MC, Price DA. Treatment of myositis ossificans progressiva with a diphosphonate. Lancet 1972; 1(7740): 10-11. doi:10.1016/s0140-6736(72)90004-9

48. Fleisch HA, Russell RG, Bisaz S, Mühlbauer RC, Williams. The inhibitory effect of phosphonates on the formation of calcium phosphate crystals in vitro and on aortic and kidney calcification in vivo. Eur J Clin Invest 1970; 1(1):12-18. doi:10.1111/j.1365-2362.1970.tb00591.x

49. Hildebrand $\mathbf{S}$, Cunningham J. Is there a role for bisphosphonates in vascular calcification in chronic kidney disease? Bone 2021: 142:115751. doi:10.1016/j.bone.2020.115751

50. Nitta K, Akiba T, Suzuki K, et al. Effects of cyclic intermittent etidronate therapy on coronary artery calcification in patients receiving long-term hemodialysis. Am J Kid Dis 2004; 44(4):680-688. pmid:15384019

51. Hashiba H, Aizawa S, Tamura K, Kogo H. Inhibition of the progression of aortic calcification by etidronate treatment in hemodialysis patients: long-term effects. Ther Apher Dial 2006; 10(1):59-64. doi:10.1111/j.1744-9987.2006.00345.x

52. Iseri K, Watanabe M, Yoshikawa H, et al. Effects of denosumab and alendronate on bone health and vascular function in hemodialysis patients: a randomized, controlled trial. J Bone Miner Res 2019; 34(6):1014-1024. doi:10.1002/jbmr.3676

53. Chen C-L, Chen N-C, Wu F-Z, Wu M-T. Impact of denosumab on cardiovascular calcification in patients with secondary hyperparathyroidism undergoing dialysis: a pilot study. Osteoporos Int 2020; 31(8):1507-1516. doi:10.1007/s00198-020-05391-3

54. Sin H-K, Wong P-N, Lo K-Y, et al. Treatment of severe tumoral calcinosis with teriparatide in a dialysis patient after total parathyroidectomy. Case Rep Nephrol 2021; 2021:6695906-6695906. doi:10.1155/2021/6695906

55. EVOLVE Trial Investigators; Chertow GM, Block GA, Correa-Rotte $R$, et al, Effect of cinacalcet on cardiovascular disease in patients undergoing dialysis. N Engl J Med 2012; 367(26):2482-2494. doi:10.1056/NEJMoa1205624

56. Raggi P, Chertow GM, Torres PU, et al. The ADVANCE study: a randomized study to evaluate the effects of cinacalcet plus lowdose vitamin $D$ on vascular calcification in patients on hemodialysis. Nephrol Dial Transplant 2011; 26(4):1327-1339. doi:10.1093/ndt/gfq725

57. Zu Y, Lu X, Song J, Yu L, Wang S. Cinacalcet treatment significantly improves all-cause and cardiovascular survival in dialysis patients: results from a meta-analysis. Kidney Blood Press Res 2019; 44(6):13271338. doi:10.1159/000504139

58. Peng T, Zhuo L, Wang Y, et al. Systematic review of sodium thiosulfate in treating calciphylaxis in chronic kidney disease patients. Nephrology (Carlton) 2018; 23(7):669-675. doi:10.1111/nep.13081

59. Udomkarnjananun S, Kongnatthasate K, Praditpornsilpa K, EiamOng S, Jaber BL, Susantitaphong P. Treatment of calciphylaxis in CKD: a systematic review and meta-analysis. Kidney Int Rep 2019; 4(2):231-244. doi:10.1016/j.ekir.2018.10.002

60. Djuric P, Dimkovic N, Schlieper G, et al. Sodium thiosulphate and progression of vascular calcification in end-stage renal disease patients: a double-blind, randomized, placebo-controlled study. Nephrol Dial Transplant 2020; 35(1):162-169. doi:10.1093/ndt/gfz204

61. Malbos S, Urena-Torres P, Cohen-Solal M, et al. Sodium thiosulphate treatment of uraemic tumoral calcinosis. Rheumatology (Oxford) 2014; 53(3):547-551. doi:10.1093/rheumatology/ket388

62. Shioi A, Morioka T, Shoji T, Emoto M. The inhibitory roles of vitamin $\mathrm{K}$ in progression of vascular calcification. Nutrients 2020; 12(2):583. doi:10.3390/nu12020583

63. Vlasschaert C, Goss CJ, Pilkey NG, McKeown S, Holden RM. Vitamin $\mathrm{K}$ supplementation for the prevention of cardiovascular disease: where is the evidence? A systematic review of controlled trials. Nutrients 2020; 12(10): 2909. doi:10.3390/nu12102909

64. Fusaro M, D'Alessandro $\mathbf{C}$, Noale $\mathbf{M}$, et al. Low vitamin $\mathrm{K} 1$ intake in haemodialysis patients. Clin Nutr 2017; 36(2):601-607. doi:10.1016/j.clnu.2016.04.024

65. Alappan HR, Kaur G, Manzoor S, Navarrete J, O'Neill WC. Warfarin accelerates medial arterial calcification in humans. Arterioscler Thromb Vasc Biol 2020; 40(5):1413-1419. doi:10.1161/ATVBAHA.119.313879

66. Nigwekar SU, Bloch DB, Nazarian RM, et al. Vitamin K-dependent carboxylation of matrix Gla protein influences the risk of calciphylaxis. J Am Soc Nephrol 2017; 28(6):1717-1722. doi:10.1681/ASN.2016060651

67. Witham MD, Lees JS, White M, et al. Vitamin K supplementation to improve vascular stiffness in CKD: the K4Kidneys randomized controlled trial. J Am Soc Nephrol 2020; 31(10):2434-2445. doi:10.1681/ASN.2020020225

68. Savinov AY, Salehi M, Yadav MC, Radichev I, Milán JL, Savinova OVI. Transgenic overexpression of tissue-nonspecific alkaline phosphatase (TNAP) in vascular endothelium results in generalized arterial 
calcification. J Am Heart Assoc 2015; 4(12):e002499. doi:10.1161/JAHA.115.002499.

69. Raggi P, Bellasi A, Bushinsky D, et al. Slowing progression of cardiovascular calcification with SNF472 in patients on hemodialysis: results of a randomized phase $2 \mathrm{~b}$ study. Circulation 2020; 141(9):728-739. doi:10.1161/CIRCULATIONAHA.119.044195

70. Alshahawey M, Borolossy R, El Wakeel L, Elsaid T, Sabri NA. The impact of cholecalciferol on markers of vascular calcification in hemodialysis patients: a randomized placebo controlled study. Nutr Metab Cardiovasc Dis 2021; 31(2):626-633. doi:10.1016/j.numecd.2020.09.014

71. Sakaguchi Y, Hamano T, Obi Y, et al. A randomized trial of magnesium oxide and oral carbon adsorbent for coronary artery calcification in predialysis CKD. J Am Soc Nephrol 2019 30(6):1073-1085.
doi:10.1681/ASN.2018111150

72. Charaghvandi DA, Teguh DN, van Hulst RA. Hyperbaric oxygen therapy in patients suffering from wounds in calciphylaxis: a narrative review. Undersea Hyperb Med 2020; 47(1):111-123. doi:10.22462/01.03.2020.12

73. Lai L-A, Hsiao M-Y, Wu C-H, Wang T-G, Özçakar L. Big gain, no pain: tumoral calcinosis. Am J Med 2018. 131(1):45-47. doi:10.1016/j.amjmed.2017.09.003

74. Gabel CK, Nguyen ED, Chakrala T, et al. Assessment of outcomes of calciphylaxis. J Am Acad Dermatol 2020; 85(4):1057-1064. doi:10.1016/j.jaad.2020.10.067

Address: Korey Bartolomeo, DO, Department of Kidney Medicine, Q7 Glickman Urological \& Kidney Institute, Cleveland Clinic, 9500 Euclid Avenue, Cleveland, $\mathrm{OH} 44195$; krbartolomeo@gmail.com

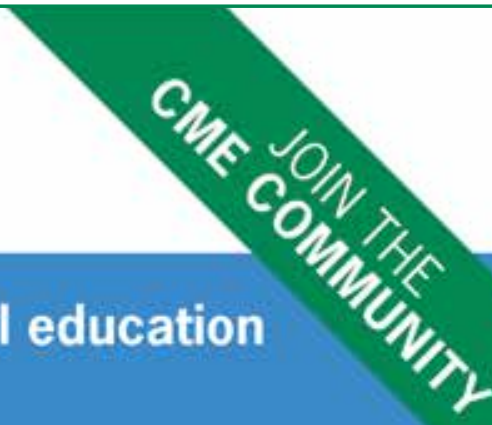

Want to make sure you are updated on medical education that is available to you?

Need to earn continuing education credits? Join our CME Community!

By becoming a part of the Cleveland Clinic Center for Continuing Education CME Community, you will always be on the cutting edge of educational opportunities available.

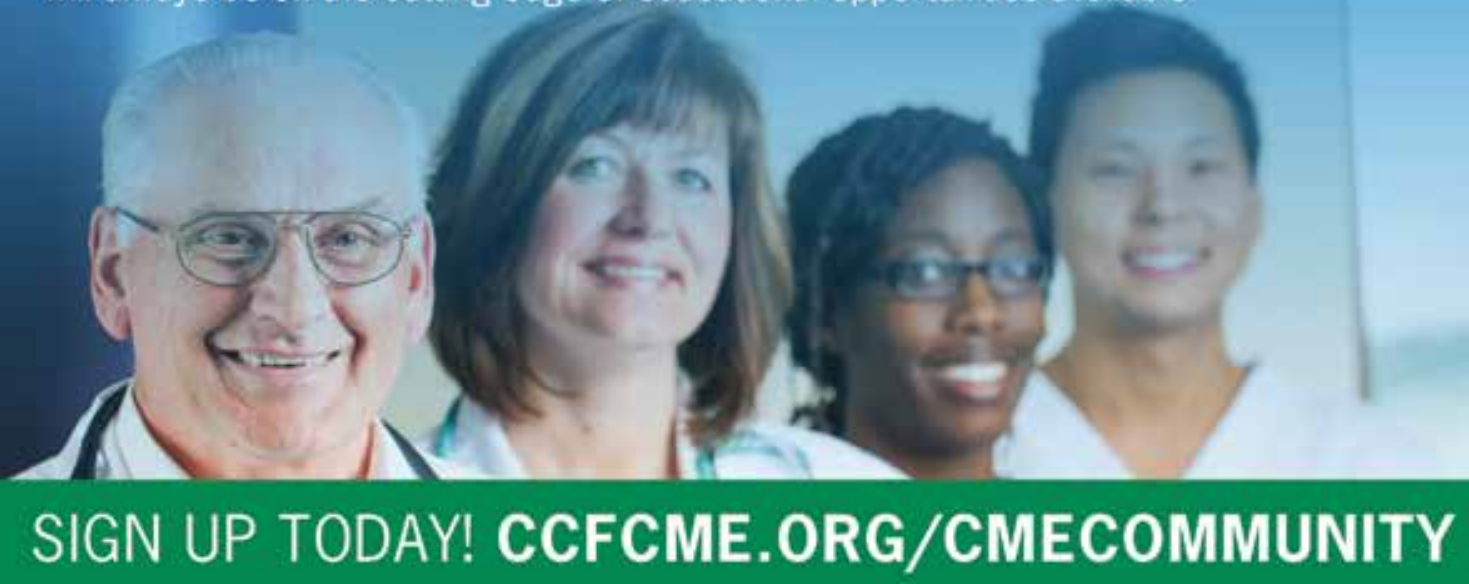




\section{CORRECTION}

In the February 2022 issue, in Bartolomeo K, Tan XY, Fatica R. Extraosseous calcification in kidney disease. Cleve Clin J Med 2022; 89(2):81-90. doi:10.3949/ccjm.89a.21073, an error appeared in Figure 1 on page 83, relative to phosphate excretion and phosphate absorption. The correct figure appears below:

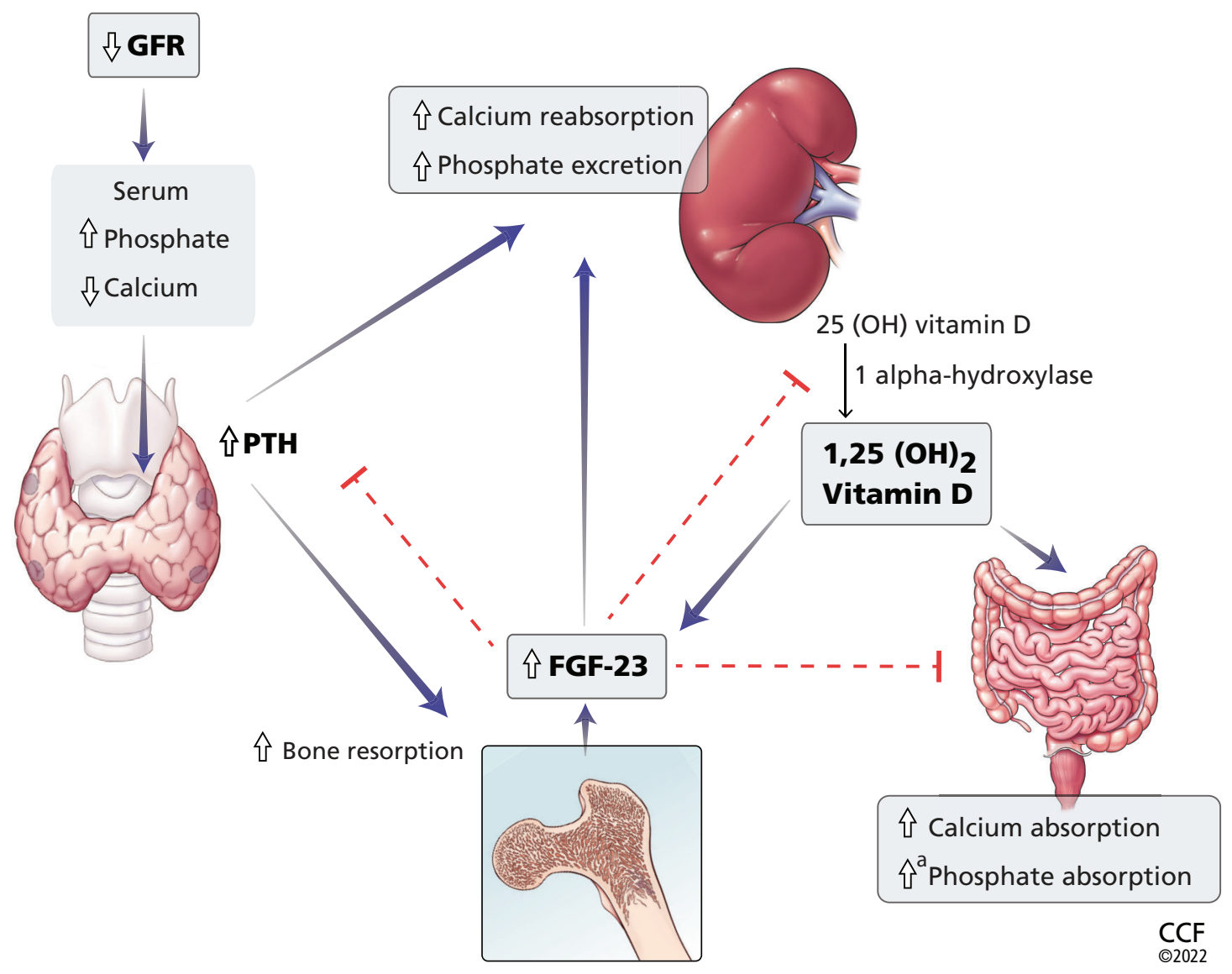

Figure 1. Calcium and phosphate metabolism in chronic kidney disease. Decreased glomerular filtration rate (GFR) leads to changes in serum calcium and phosphate, triggering release of parathyroid hormone (PTH) from the parathyroid glands and fibroblast growth factor 23 (FGF-23) from osteoblasts and osteocytes. These hormones have complex downstream effects on the kidney, gut, and bone, both from direct effects on the tissue and from indirect effects through modulation of enzyme activity in vitamin $\mathrm{D}$ conversion.

${ }^{a}$ Minimally increased.

$25(\mathrm{OH})$ vitamin $\mathrm{D}=25$-hydroxycholecalciferol; $1,25(\mathrm{OH})_{2}$ vitamin $\mathrm{D}=1,25$-dihydroxycholecalciferol

This is now correct on ccjm.org. 